\title{
Robert Boyle and Mathematics: Reality, Representation and Experimental Practice
}

\section{Citation}

Shapin, Steven. 1988. Robert Boyle and mathematics: Reality, representation and experimental practice. Science in Context 2(1): 23-58.

\section{Published Version}

http://dx.doi.org/10.1017/S026988970000048X

\section{Permanent link}

http://nrs.harvard.edu/urn-3:HUL.InstRepos:3403065

\section{Terms of Use}

This article was downloaded from Harvard University's DASH repository, and is made available under the terms and conditions applicable to Other Posted Material, as set forth at http:// nrs.harvard.edu/urn-3:HUL.InstRepos:dash.current.terms-of-use\#LAA

\section{Share Your Story}

The Harvard community has made this article openly available.

Please share how this access benefits you. Submit a story.

Accessibility 


\section{STEVEN SHAPIN}

\section{Robert Boyle and Mathematics: Reality, Representation, and Experimental Practice}

\section{The Argument}

This paper is a study of the role of language in scientific activity. It recommends that language be viewed as a community's means of patterning its affairs. Language represents where the boundaries of the community are and who is entitled to speak within it, and it displays the structures of authority in the community. Moreover, language precipitates the community's view of what the world is like, such that linguistic usages can be taken as referring to that world. Thus, language connects on the one side to a community's practical life, and, on the other, to the reality on which it "reports."

The example treated is Robert Boyle's view of the language proper for experimental practice, and his arguments against the value and legitimacy of mathematical representations within the experimental community. Boyle argued that the use of mathematics was inappropriate because (i) it would restrict the number of potential participants; (ii) it would give rise to unwarranted expectations of the certainty and accuracy to be expected of real physical inquiries; (iii) it would suggest views of natural law and God's relations with the natural world which were incorrect and possibly dangerous; and because (iv) the world upon which the experimentalist operated was not such as was represented by mathematical idealizations. I try to establish that decision about the appropriate language for the experimental community was a moral choice.

\section{The Book of Nature and the Natural Philosophical Form of Life}

It was one of the commonplaces of early modern philosophical discourse that nature had the status of a text and that natural philosophical exercises were hermeneutic in character. To Paracelsus, for example, the second book of medicine was "the firmament": "It is possible to write down all medicine in the letters of one book, to the end that everyone may learn it by reading the book, and the firmament is such a book... [T] The stars in heaven must so be taken together in order that we may read the sentence in the firmament... It is like a letter that has been sent to us from a 
hundred miles off, and in which the writer's mind speaks to us ..." (Paracelsus 1951, 159; see also Hacking $1975,39,41$ ). In the 1660s Boyle wrote that "each page in the great volume of nature is full of real hieroglyphicks, where (by an inverted way of expression) things stand for words, and their qualities for letters" (1772, 2: "Usefulness of Experimental Natural Philosophy," 29; cf. ibid., 6, 8). The world was, as St. Augustine said of the sacraments, verbum visibile. ${ }^{1}$

Examples of this conceit could be multiplied almost indefinitely. Moreover, as Ian Hacking and others have rightly stressed, the image of nature's book was neither a mere literary trope nor an empty aesthetic analogy. ${ }^{2}$ The Book of Nature was understood to be literally, and divinely, authored. The language in which God elected to compose his Book of Nature set the frame of reference for the natural philosophical enterprise. It determined the nature of the decoding process that defined natural philosophy, and it licensed the use of the particular language of natural philosophical discourse.

Yet natural philosophers themselves had to decide what the language was in which God had written his Book of Nature, and in the sixteenth and seventeenth centuries there was considerable disagreement on this subject. Some said that its language was mathematical. According to Galileo,

Philosophy is written in this grand book, the universe, which stands continually open to our gaze. But the book cannot be understood unless one first learns to comprehend the language and read the letters in which it is composed. It is written in the language of mathematics, and its characters are triangles, circles, and other geometric figures without which it is humanly impossible to understand a single word of it; without these one wanders about in a dark labyrinth. ${ }^{3}$

Robert Boyle found occasion to quote Plato, saying that "the world was God's epistle written to mankind," and that "it was written in mathematical letters" $(1772,4$ : "Excellency and Grounds of the Mechanical Hypothesis," 77; also quoted in ibid., 2: "Usefulness of Experimental Natural Philosophy," 29). But some philosophers, including, for example, Pascal and Leibniz, and (as I shall show) Boyle himself, had major reservations about construing the Book of Nature as composed in the language of mathematics (see Koyré 1968, 38 [note]).

My starting point is this: the practical work of natural philosophy was predicated upon a choice of its proper language. Since the choice of the appropriate language for natural philosophy was seen to follow from one's appreciation of the language in which the divine Book of Nature was written, authentic natural philosophy could

I For the hieroglyphic image and the interpretation of natural signs in the seventeenth century, see Eisenstcin 1980, 471; Foucault 1970, chap. 2, esp. 26-27, 29, 35. A relevant literature is concerned with sixtecnth-and sevententh-century Books of Secrets and their interpretation; see Eamon 1984, 1985.

: Hacking 1975, chap. 5. For a range of invocations of the Book of Nature, see esp. Eisenstein 1980, 45-56. 471-72. 474-76, 486, 629, 657 (for Bacon, Descartes, Kepler, Libavius, and Thomas Browne); Hannaway 1975, 61-67, 106-7, 110-14 (for Croll and Libavius); and Dillenberger 1960, 112-17 (for Boyle).

Galiko Galilei, "The Assayer (excerpts)," in Galileo 1957, 237-38. On Galileo and the mathematical Book of Nature, see also Bochner 1966, 187; Koyré 1968, esp. 13-14, 19, 34, 90; and Burtt 1954, 75. 
only claim legitimacy if the two languages - natural and human - were in fact related. In order that the importance of linguistic choice be understood, I must argue against any sensibility that regards the language of an intellectual activity merely as the medium for the articulation and communication of prerepresentational ideas. On the contrary, I want to recommend a more embedded and a more structural conception of the place of language and of the significance of linguistic choice in practical activity. I wish to treat language as a community's means of patterning its affairs. Language carries the social relations of the community; it represents the structures of authority within the community; and it signals to members and to others where the community's boundaries are located and what the costs and benefits of traversing them may be. Language, understood this way, is the vehicle of communal life.

Further, I want to argue that linguistic activity precipitates the community's ontology, its theory of what the world is like, such that the community's language can be matter-of-factly treated as reliably referring to that world. And, since this is so, the community's language will give materials for making representations which are taken to be suitable accounts of what the world is like. Linguistic structures therefore connect, on the one side, with ontology, and, on the other, with representation. But they center upon the life of the community. In the historical examination of linguistic structures we are dealing with the documentary residues of communal forms of life.

The Wittgensteinian resonance is intentional. I want to start by discussing language and language choice, and I want to end by displaying choice about the proper form of life for a philosophical community. We transit the notion of a language game, and this is a particularly useful notion if we wish to highlight the embeddedness of language in patterns of activity. For Wittgenstein "the term 'language-game' is meant to bring into prominence the fact that the speaking of language is part of an activity or of a form of life" (Wittgenstein 1976, I, 23, p. 11; see also Bloor 1983, chap.3). In such a conception, language is not, as it is for idealist historians or many literary theorists, prior to activity or even a determinant of practical activity. For Wittgenstein, language is itself an activity, and it is embedded in overall structures of activity. Elsewhere, Simon Schaffer and I have argued that practical solutions to the problem of knowledge are also solutions to the problem of social order (1985). ${ }^{4}$ In the present connection I want to argue for a special instance of that general principle. I want to show that solutions to the question of what was the correct language for scientific intellectuals were simultaneously solutions to the question of what natural reality was like and to the problem of what form the social life of the relevant scientific community should take.

I will examine a situation in which members of a philosophical community were confronted with choices about the proper language to be used. Members do not always experience choice in these matters. Stable and institutionalized language-

\footnotetext{
${ }^{4}$ For historical studies of science that urge, to varying degrees, the power or primacy of language, see, for example, Anderson 1984; Cantor 1979, 17-19; Cantor 1985 (especially interesting for its handling of actors' disputes over the potency of language). For an extended study of language as part of practical scientific activity, see Shapin and Schaffer 1985, esp. chap. 2.
} 
using communities pass on their linguistic practices routinely and unproblematically, reinforcing members' sense of self-evident correspondence between reality and representation. Nevertheless, there are major analytic advantages to the study of episodes of choice. For example, we can hardly argue for the power of language to compel action when we see actors deciding which language to employ, and mobilizing justifications in their causes. The evidence of those justifications in situations of choice also allows us to see more clearly than usual the range of considerations implicated in the community's language use. In the episodes studied here, a community was confronted with choices about its proper language, proper ontology, and proper social and moral conduct. I will try to show how these choices were structurally connected and what considerations bore upon the choice of language.

The example I discuss concerns a series of arguments advanced in the middle and latter part of the seventeenth century by Robert Boyle and presented by him to the emerging community of experimental philosophers. These arguments may strike many students of the development of seventeenth-century science as distinctly odd or even retrograde, because they were arguments against the propriety of mathematical language for the natural philosophical community. To be as precise as possible, I must say that Boyle did not argue against mathematics itself nor even against its value in certain prescribed philosophical tasks. What he did do was to proffer a series of reasons why the language of mathematics was grossly inappropriate to a number of exercises central to the role of the experimental philosopher and to the form of life recommended for the experimental community.

\section{Boyle as Mathematician}

A straightforward answer to the question of why Boyle did not produce nor commend a mathematical chemistry and a mathematical physics already exists in the historical literature. It is a satisfyingly simple answer: Boyle did not speak the language of mathematics because he was not able to do so; he was mathematically incompetent at the relevant level, if not mathematically illiterate. According to one of his biographers, Boyle himself "admitted he was so deficient he could not use mathematical analysis in his work" (More 1944, 64). Indeed, in his 1671 essay "Of the Usefulness of Mathematicks to Natural Philosophy," Boyle did say that "I have often wished, that I had been employed about the speculative part of geometry, and the cultivating of the specious Algebra I had been taught very young, a good part of that time and industry, that $I$ spent about surveying and fortification ... and other practick parts of mathematicks.... I do not pretend to have taken that pains, which clse I might have done, to become a speculative geometrician ..." $(1772,3: 425) .{ }^{5}$ In

"This text is part of "Some Considerations Touching the Usefulness of Experimental Natural Philosophy ... The Second Tome," (Boyle 1772, 3:392-456). See also Maddison 1969, 31(note). On Francis Bacon s alleged lack of skill in mathematics and his consequent devaluation of its role in natural science, sce Jones $1961,110$. 
his original (1660) reports of experiments with the air-pump, Boyle excused his eschewal of physical generalization because this would "require more skills in mathematics than I pretend to ..." (1772, 1: "New Experiments Physico-Mechanical," 36). And in "The Excellency of Theology compared with Natural Philosophy" he described himself as one "who pretend[s] not to be a mathematician" (Boyle 1772, $4: 22){ }^{6}$

Other historians, citing other evidence, have sprung (as they supposed) to Boyle's defense. Marie Boas [Hall] claimed that Boyle was in fact "well-educated in the mathematical sciences"; he was, she said, "by no means ignorant either of mathematics or of the mathematical sciences" $(1958,13,36)$. Writing to his father while on the "Grand Tour of the Continent" with his tutor Isaac Marcombes in 1642, Boyle noted that, "We continue our Study in the Mathematickes which is (as I thinke) the bravest Science in the world (after Divinity), and I hope to become a good proficient therein...."7 In 1647, having reached his majority, he wrote to Samuel Hartlib that he was reading Oughtred's Clavis mathematica, which "does much content me," and that he was seriously engaged in a program of mathematical studies (Boyle to Hartlib, 8 May 1647, in Boyle 1772, 1:xli). In 1652 Boyle referred to "those excellent sciences, the mathematics, having been the first I addicted myself to" (1772, 1: excerpts from "Considerations on the Style of the Scriptures," xlix; see also Boas [Hall] 1958, 22). By 1654, according to Thomas Birch, "He had before laid in a great stock of mathematical knowledge," and he was recognized as sufficiently adept for John Wallis to dedicate his 1659 tract on cycloids to him, extolling Boyle's mathematical abilities (Boyle 1772, 1:lv, lix; Wallis 1693-95, 1:491). Gilbert Burnet judged that Boyle "had run the whole compass of the mathematical sciences; and though he did not set up for an inventor in them, yet he knew even the abstrusest parts of geometry" (Burnet 1742, 208-9, quoted by Birch, in Boyle 1772, 1:cxliv). From what evidence we have, it would seem that Boyle's education at Eton and by his tutor in the mathematical sciences was broadly similar to that described by Feingold for English gentlemen in the early- to mid-seventeenth century. The stress was upon the practical parts of mathematics (especially fortification and surveying), and fed into the gentry's current infatuation with mechanical devices as "artificial miracles" and with experimental displays valued "for their novelty or prettiness" (Feingold 1984, chap. 6, esp. 193-95; Boyle 1772, 3: "Origin of Forms and Qualities," 5; Moran 1981, 273; Gascoigne 1985, 413-17; Zetterberg 1976, 45-54; Turner 1973). Of course, much (probably most) of the mathematics Boyle knew in his mature years was derived from self-study, and was heavily influenced by his colleagues at Oxford from the mid$1650 \mathrm{~s}$.

Given the ambiguous state of the evidence regarding Boyle's actual mathematical skills, it is fortunate that nothing I wish to say depends upon determining the real state of affairs. I shall be concerned partly with the deployment or nondeployment of

'See also Boyle 1772, 1: "Defence against Linus," 122, where Boyle gave his poor eyesight as a reason for his avoidance of studying "mathematical schemes."

7 Robert Boyle to his father, Lyons, 15 May 1642, in Grosart 1887, 5:114 (as quoted in Jacob 1977, 10). 
mathematics in Boyle's experimental practice, and mainly with the explicit arguments he mobilized concerning the proper place of mathematical language and orientations in the practice of the nascent community of experimental philosophers. One can imagine a situation in which those arguments were a rationalization for genuine mathematical incompetence, and one can equally imagine that Boyle rejected his actual mathematical skills in favor of alternative practices, the superiority of which he deeply felt. It is this latter possibility that most appeals to Marie Boas [Hall,] who very perceptively noted the public status of Boyle's arguments against mathematical modes of reporting. Boyle, she says, "notoriously avoided mathematical language. But this ... was a pose more than a fact, a deliberate adoption of a manner, designed to aid him in debate" (Boas [Hall] 1958, 34). This is an intriguing, if highly speculative, theory, and it may well be correct. But my focus is elsewhere. Whether Boyle could or could not compose natural philosophy in the language of mathematics, he was certainly in the practice of giving public reasons why he was not doing so, and importantly, of offering public recommendations why others should follow his example. As in the great bulk of his experimental reports, Boyle was simultaneously doing experimental science and setting a model for how an experimental community should conduct its affairs.

In the cause of precision I must start by confronting evidence which seems to show Boyle's positive evaluation of mathematics or of its legitimate place in experimental philosophy, or which appears to establish crucial incorporations of mathematical language into Boyle's experimental practice. Some of this evidence does, as we shall see, illustrate ways in which Boyle did applaud mathematics and its uses in specific contexts. In other instances, however, the evidence that Boyle approved of a central role for mathematics in experimental philosophy is weak or illusory, and is counterbalanced by strong and reiterated arguments as to why the role of mathematics should be rigorously limited. To repeat, Boyle was not arguing against mathematics, but only against the appropriateness of its use as the language of experimental practice.

\section{The Case for Mathematics: Circumstance, Measure, and Mechanism}

It is necessary here briefly to specify the sense in which the word "mathematics" is being used, not least to guard against conflating radically different seventeenthcentury and present-day denotations. In the seventeenth century the term "mathcmatics," "the mathematics," and "the mathematical sciences" were far more culturally inclusive than is the term "mathematics" at present. As Thomas Kuhn has noted, the legacy of mathematical sciences inherited from antiquity by the seventeenth century included, in addition to the "pure mathematics," subjects in physical inquiry like astronomy, optics, statics, and even musical theory. All of these had traditionally been closely associated with the use of geometry and, Kuhn says, "might better be described as a single field, mathematics" (1977, 36-37; see also 
Bennett 1982, chap. 2). Within that broad span of cultural activity so designated, distinction was made between "pure" (or "speculative" or "abstract") and "mixed" mathematics. Moreover, seventeenth-century senses of the boundaries of mathematics also stretched to encompass activities whose methods were deemed to be characteristic of pure mathematics and particularly of geometry. Thus, the application of the methods of logic, including the syllogistic mode of demonstration, was routinely referred to as "mathematical." We will see below how Boyle's arguments dealt with all these aspects of mathematical culture.

I have been able to distinguish six senses in which Boyle either deployed mathematics in his experimental practice, explicitly approved of its role in the overall culture, or apparently commended its central place in his natural philosophy.

The first possibly ought not to be dignified with the term "mathematics" at all, even though it was an important usage for Boyle. Boyle significantly employed number in the vocabulary of his experimental language. While in very many instances he was content to report that a particular experiment had been tried "divers times," or that a certain piece of glassware was "divers feet" in length, in others he was at pains to specify exactly how many times an experiment was tried, precisely how many movements of the air-pump piston were required to achieve a certain effect, just how far the mercury in the glass subsided, exactly how long the tube was, and so forth. Elsewhere, I have tried to show what role was played by highly circumstantial reporting in Boyle's experimental practice (Shapin 1984). Boyle, I argued, was attempting to develop for himself, and to encourage in others, a prose style that served to paint a picture of reality for the readers of his narrative texts. These readers were to be recruited as "virtual witnesses" of real experimental scenes that were reported in his texts. By providing the richly textured circumstantial detail that included quantitative circumstances as an element, Boyle aimed to facilitate an increase in the size of the community of witnesses to experimental performances. Such detail might, it was said, facilitate the actual replication of experiments by readers, but it might also, without replication, provide adequate assurance that the experiments were actually performed. A reader who believed the reportorial reliability of these prose pictures would count as an effective member of the witnessing community (Shapin and Schaffer 1985, chap. 2; Eisenstein 1980, 470; Dear 1985 and 1987; Golinski 1984, esp. 84-97). ${ }^{8}$

A second, and related, usage involved the employment of number as scalar measure of physical qualities. There were many contexts in which Boyle's concern for the exact numerical specification of physical qualities emerged, but one of the most illuminating involved his work on hydrostatical techniques for assessing the purity of chemical, pharmaceutical, and mineral substances. Thus, in his "Medicina Hydrostatica" of 1690 Boyle lamented the lack of adequate universal metrological standards $(1772,5: 487)$. The Roman grain was, he complained, different from the

${ }^{8}$ It is worth noting that the program of actual experimental replication that Boyle attempted to encourage was a substantial failure and was recognized by him to be so; see Shapin and Schaffer 1985, chap. 6 . 
French grain; and in his "New Experiments Physico-Mechanical" of 1660 Boyle pointed out that "our English inches are somewhat inferior in length to the digits made use of in foreign parts" (1772, 1:38). Until these and similar differences were reconciled, or at least fully recognized, experimental replication would be very difficult or impossible. The experimentalist, however competent, would not be able to tell whether or not he had successfully replicated a trial reported by another experimentalist living in a different metrological culture. There is, therefore, no doubt that the achievement of a degree of metrological precision was deemed essential to the furtherance of experimental practice and to the extension of experimental culture.

Third, Boyle approved of mathematics as a tool appropriate in principle for investigating the properties of his corpuscular and mechanical universe. A physical reality whose ultimate constituents were geometrically figured particles, arranged into various geometrical "textures" and subject to definite states of motion, was such a reality as lent itself to mathematical construal and representation (Kuhn 1952, 1718; Boas [Hall] 1958, chap. 3; Boas [Hall] 1959). ${ }^{10}$ As Burtt put it, the "mathematical view of nature involves, of course, a mechanical conception of its operations" (1954, 173). And Boyle delivered his views on this subject at length:

... I can scarcely think men will be able to know all the propertys and uses even of familiar Bodys \& other things, till they have mathematically consider'd them, there being several attributes belonging even to such things which a naturalist tho curious will probably never find out unlesse he be both acquainted with mathematicall Disciplines, \& have the curiosity to apply them to Phisicall subjects. ${ }^{11}$

Moreover, the mathematical disciplines

teach men the nature and properties of figures, both upon surfaces and solids... It is true, that matter, or body, is the subject of the naturalist's speculations; but if it be also be true, that most, if not all the operations of the parcels of that matter ... depend upon those modifications, which their local motion receives from their magnitude and figure ...; it can scarce be denied, that the knowledge of what figures are ... must be of considerable use in explicating many of the phenomena of nature. (1772, 3: "Usefulness of Mathematicks," 427.)

A repertoire of geometrical knowledge could be applied, if only by rough analogy, to the understanding of a corpuscular universe. The ideal world of geometry might indeed correspond to a real but invisible world that underpinned Boyle's corpuscular and mechanical philosophy. For that reason alone, a role for geometrical representation in physical inquiries was, in principle, legitimate. Here, and in other connections, a "competent knowledge of mathematics" (although not necessarily a

- For Nersenne's problems with non-standarid measures, see Koyré 1968, 99.

to For discussion of chemical "texture," see Alexander 1985, 58, 60-61, 66, 74-79.

"Boyle to Henry Oldenburg, n.d., in Royal Society, Boyle Papers, vol. 25 (as quoted in Boas [Hall] 1958, 36). 
"profound" one) was, Boyle said, "serviceable" to the experimental philosopher (1772, 3: "Usefulness of Mathematicks," 426).

\section{The Case for Mathematics: Right Reason and Right Religion}

Fourth, Boyle commended mathematics, and especially pure mathematics, as a general form of culture and as training for the mind. He claimed that "these disciplines are wont to make men accurate, and very attentive to the employment they are about, keeping their thoughts from wandering. ..." "The modern Algebra," Boyle said, was "one of the clearest exercises of reason that I ever yet met with...." Mathematical study and application habituated the mind to rational activity. Thus, mathematics was commended not just to the experimental philosopher, but to the educationalist and to all concerned to set culture on a more rational footing (Boyle 1772, 3: "Usefulness of Mathematicks," 426). ${ }^{12}$

Fifth, Boyle identified the specific contributions that mathematics might make to the erection and protection of right religion and right methods of evaluating testimony and experience in light of reason. In his 1681 "Discourse of Things above Reason," Boyle set out to display the proper place in religious belief of matters inaccessible to human reason..$^{13}$ It was, for example, right to believe in the existence of God and incorporeal spirits even though these are entities the nature of which we cannot comprehend. It was likewise right to believe both in man's free will and in God's perfect foreknowledge, even though these two truths were, in Boyle's terminology, "unsociable," viz., "we see not how to reconcile [the one] with some other thing, that we are perswaded to be a truth" (1772, 4: "Discourse of Things above Reason," 407). Even so, it was necessary to specify sufficient causes for assenting to that which was above reason, in other words, to have a rational warrant for a belief that appeared to conflict with reasonable belief. These sufficient causes were of three sorts: experience, authentic testimony (including, of course, divine testimony), and mathematical demonstration.

Mathematical instances were adduced to show the propriety of belief in that which could not be rationally conceived by the human mind. For example, Boyle liked to point to our assent to the claim that the diagonal of a square was incommensurable with its sides as an instance of justified belief in something we could not rationally comprehend. Infinite divisibility of a finite length, and degrees of infinity, were also

${ }^{12}$ For Torricelli's view that "geometry alone exercises and sharpens the mind," giving it "a quite particular and virile strength," see Koyré 1968, 39. And see the familiar discussion of Puritan perspectives on reason, mathematics, and physics in Merton 1970, 66-68. In Boyle's autobiographical "An Account of Philaretus during His Minority," he described how "the Extractions of the Square \& Cubits Rootes, \& specially those more laborious Operations of Algebra" were expedients "likelyest to fetter (or at least, to curbe/bridle) the rouing wildnesse of his wandring ... Thoughts" (printed in Maddison 1969, 2-45, on 17).

${ }^{13}$ For background to this important text, see, for example, Westfall 1973, 169-71; Klaaren 1977, 129-46. 
adduced in this cause. ${ }^{14}$ Mathematical demonstration supplied us with a species of "positive proof." It offered a model of compelled and necessary assent to

those consequences, that are clearly and legitimately inferred from any manifest acknowledged, or already demonstrated truth. To this sort [of positive proof] belong divers mathematical propositions and corollaries, which though being nakedly proposed they seem incredible to the generality of learned men, and sometimes to mathematicians themselves, are yet fully assented to, because they clearly follow from either manifested or demonstrated truths. (Boyle 1772, 4:

"Discourse of Things above Reason," 456.)

Certain of Euclid's propositions were, therefore, necessarily true - we were obliged to assent to them - yet they were inconceivable and incomprehensible. It was not to count as a derogation of mathematics nor of natural philosophy that they contained such inconceivable yet true elements, just as it was no slight on religion that we could not ask for the matters of fact related in the Gospels to be demonstrated (Boyle 1772, 6: "The Christian Virtuoso, Appendix," 713). ${ }^{15}$ Bodies of culture were, in Boyle's view, differentiated according to appropriate means of securing assent, degrees of certainty, and methods of warranting items of knowledge: "It is not just to require other proofs of things, than such as, in case it be true, the nature of it will bear" (1772, 6: "The Christian Virtuoso, Appendix," 681).

While stressing that mathematical demonstration might not be entirely appropriate in forms of culture other than its own proper domain, Boyle agreed with a wide range of English seventeenth-century thinkers in pointing to mathematics as a model of compelled assent. Barbara Shapiro has written that "there was relatively little disagreement [in seventeenth-century England] that demonstration, particularly mathematical demonstration, was the most certain knowledge of all" (Shapiro 1983, 31). Glanvill said that mathematical science possessed "uncontroverted certainty," and Boyle concurred: "In pure mathematicks, he, that can demonstrate well, may be sure of the truth of a conclusion, without consulting experience about it ..." (Glanvill 1661, 160; Boyle 1772, 2: "Hydrostatical Paradoxes," 742; and see Shapiro 1983, 32, 275-76). Were mathematics, and the demonstrative method, not the highest form of knowledge and the most proper way of establishing knowledge?

Finally, we come to an apparent usage of mathematics in Boyle's experimental practice with which everyone is familiar. This is the use of mathematical representation to express natural regularities. For if we know nothing else about Boyle, we know that he enunciated "Boyle's Law" symbolically relating the pressure and

"Boyle 1772.4: "Discourse of Things above Reason," 408 ("But though mathematical demonstrations assure us, that these things are so, yet those, that have strained their brains, have not been able clearly to conceive how it should be possible, that a line (for instance) of not a quarter of an inch long should be still divisible into lesser and lesser portions, without ever coming to an end of these sub-divisions ..."); cf. 4:445; on the incommensurability of the diagonal, see also ibid., 6: "The Christian Virtuoso, Appendix to the First Part," 688-89; ibid.: "The Christian Virtuoso. The Second Part," 754-55; and see Westfall 1973, 169.

"For Bishop Berkeley's identification of mystery in the calculus and his preference for mystery in religion, see Cantor 1984. 
volume of gases. Here, it would seem, is clear evidence for an absolutely central deployment of mathematical language in Boyle's program of experimental philosophy - the statement of a mathematically formulated law of nature that holds universally and that expresses the real underlying structure of natural reality.

I have now pointed to a series of uses of mathematics by Boyle in his experimental practice, or of apparent uses, or of laudatory remarks about mathematical culture in reference to the overall culture or religion. I want now to focus specifically upon experimental practice, and I want to identify the strict limits that Boyle imposed upon the deployment of mathematics in that practice. These limitations and restrictions were expressed in explicit arguments which Boyle enunciated repeatedly throughout his working life. The arguments against aspects of mathematics amounted to the delineation of a form of life for experiment in which mathematical representations and mathematical methods of securing assent were grossly inappropriate. On the one hand, mathematical representations of reality pointed to an improper ontology; on the other, mathematical means of persuasion were embedded within an improper, even immoral, social order.

\section{Did Boyle Write "Boyle's Law"?}

Boyle did not write "Boyle's Law." This claim is at once trivially true and deeply significant. He did not, of course, write any representation of that law that took the symbolic form: $P_{1} V_{1}=P_{2} V_{2}$ (where $T$ is constant), nor did he write $P V=k$, nor even $\mathrm{P}_{1} / \mathrm{P}_{2}=\mathrm{V}_{2} / \mathrm{V}_{1}{ }^{16}{ }^{16}$ There were in the middle of the seventeenth century probably only three mathematically expressed laws of nature in terrestrial physics: the law of reflection (known in antiquity); Descartes' law of refraction; and Galileo's law of free fall. All of these were represented in geometrical rather than algebraic form (Cohen 1980, 33-34). This much is, perhaps, obvious, but it is rather less obvious that the reference of the relationship now understood to be indicated by "Boyle's Law" was not that understood by Boyle himself. For Boyle, the relationship between pressure and volume applied not universally to the set of "gases" but to the unique and variable substance "atmospheric air." The set of natural kinds designated "gases," containing the mixture "air" and other members like "nitrous oxide," "oxygen," and "carbon dioxide," did not come into the natural philosopher's vocabulary until long after Boyle's time (Boas [Hall] 1958, 216).

If Boyle did not enunciate a mathematically formulated universal relationship between the pressure and volume of gases (our "Boyle's Law"), what did he actually do? The procedures which generated his expressed findings were exceptional enough, both in terms of his own normal practice and in terms of the natural

${ }^{16}$ For background to Boyle and his "law," see Webster 1965; Agassi 1977, 197-99; Conant 1970a, 1:56. For formulations of "Boyle's Law," see Brush 1983, 17-18; and for a standard textbook exposition, see Lee 1935, 265 66. For excellent sensitivity to the historical referent of "Boyle's Law," see Ravetz 1971, 204 (note); cf. Cohen 1980, 26-27. 
Table 1. A table of the condensation of the air

E

$\mathrm{D}$

\begin{tabular}{lc}
\hline $309 / 16$ & $30^{6 / 16}$ \\
$31^{15 / 16}$ & $31^{12 / 16}$ \\
$35^{5 / 16}$ & $35-$ \\
$41^{10 / 16}$ & $41^{2 / 17}$ \\
$47^{1 / 16}$ & $46^{3 / 5}$ \\
$67^{1 / 16}$ & $66^{4 / 7}$ \\
$93^{1 / 16}$ & $93^{1 / 5}$ \\
$117^{9 / 16}$ & $116^{4 / 8}$ \\
\hline
\end{tabular}

Excerpted from Boyle 1772, 1:

"Defence against Linus," 158 (orig. publ. 1662).

philosophy of the mid-seventeenth century. He set out to test a hypothesis and did so by producing and comparing two sets of numbers, as presented in Table $1 .{ }^{17}$

In the above table column $D$ is the sum (in inches) of the height of the mercury column in the longer leg of the J-tube (column B in the original) and the height of mercury sustained by the atmosphere (column $\mathrm{C}$ in the original), taken here to be $29 \frac{1}{8}$ inches - although a typographical error in the 1772 edition gives $22 \frac{1 / 8}{8}$ inches. Column $\mathrm{E}$ is captioned: "What that pressure ought to be according to the Hypothesis, that supposes the pressures and expansions to be in reciprocal proportion." Note that no corresponding values in $\mathrm{D}$ and $\mathrm{E}$ agree exactly, although one reading in the "Table of Rarefaction" which follows in the text does so agree.

Column $\mathrm{E}$ of this well-known table consists of results expected on theory, and column D of actual experimental findings. The validity of the hypothesis was to be assessed by the goodness of fit between the two columns. While comparisons of the predicted with the actual were fairly common in astronomy, the use of tabular forms to produce numerical comparisons in terrestrial natural philosophy was very rare at the time. Galileo, we know, did systematically compare predicted and observed values, but he did not print these findings (Drake 1985:5-6). ${ }^{18}$

With respect to Boyle's own normal practice, such numerical comparisons were never to be repeated. They were, however, a feature of the work of Boyle's assistants Robert Hooke and Denis Papin. Thus, we find in a 1682 text under Boyle's name this statement of the law: "The remaining space : the total space :: the first pressure : the

"For a table by Hooke and data by Power and Towneley relating to "Boyle's Law," see Hooke 1665, 226: Power 1664, 121-30. For Boyle's similar table of rarefaction, see 1772, 1: "Defence against Linus," 160.

* For a discussion of the historical relationship between theory and experiment and a critique of the standard textbook account, see Kuhn 1977 b. 


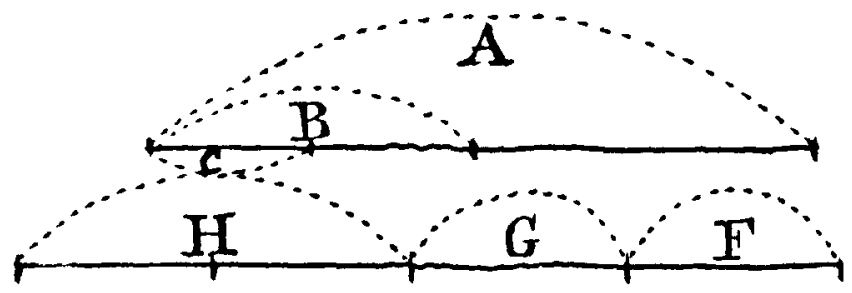

Figure 1. Schematic representation of "Boyle's Law." $A$ represents the space occupied by a certain quantity of air when the compressing force is $F$. If that force is increased by the addition of $G$, then the space occupied is reduced to $B$ (which equals $A / 2$ ). If force $H$ is added, so that $F$ is $1 / 4$ the total pressure $F+G+H$, the air then occupies space $p C$, which is $1 / 4$ total space $A$. (Source: Boyle 1772, 4: Icon. 2, fig. 2.)

total pressure," and indeed a schematic representation of the law as shown in figure 1 (Boyle 1772, 4: "Continuation of New Experiments, Physico-Mechanical ... The Second Part," 512). However, despite Boyle's formal status as author of this text, it is virtually certain that it was mostly (and possibly wholly) written by his then assistant Papin. ${ }^{19}$ There is also a striking instance of a contemporary theory-data table in a letter from Hooke to Boyle dated 29 October 1664, in which Hooke included a table of the refractive capacities of water, brine and oil of turpentine. Hooke's table systematically compared "observed" and "hypothetical" angles (Boyle 1772, 6:49697; and cf. Hooke 1665, "Preface," sig. $\left.\mathrm{fr}^{\mathrm{r}-\mathrm{v}}\right)$. Although I am not at all concerned here with reattributing authorship of "Boyle's Law," nothing in this discussion counts against the contention that Hooke had substantial responsibility for the form in which Boyle represented it (in this connection see Pugliese 1982, esp. 146-201; Centore 1970, 52-60).

With regard to Boyle's presentation of his table, it is well known that he was stung into producing this exceptional numerical comparison for a very specific occasion. Shortly after the publication of his "New Experiments" in 1660, the Jesuit natural philosopher Franciscus Linus disputed Boyle's interpretations, and specifically impugned the competency of Boyle's central mechanical construct, the "spring of the air." An Aristotelian antimechanist, Linus claimed that the air's spring was not sufficiently powerful to counterpoise a column of mercury 29 inches high, and that a so-called "funiculus" (a threadlike entity elaborated from the mercury which pulled the column up) was necessary to account for the findings of the Torricellian experiment. Boyle performed further experiments, including those in the specially designed $\mathrm{J}$-tube that generated pressures higher than atmospheric, to refute Linus.

${ }_{19}$ In the preface to this tract Boyle himself said that he had desired Papin "to set down in writing all the experiments and phenomena" made with Papin's own air-pump, and that Boyle "was enforced to leave the choice of words" to Papin as well. Moreover, in the section of the text where this formulation of the law occurs, "Mr. Boyle" is explicitly referred to as an authority, a practice never used by Boyle himself (Boyle 1772, 4: "A Continuation of New Experiments, Physico-Mechanical ... The Second Part," 506-7, 512). 
that without the assistance of his Funiculus...." Numerical measures expressed the real power and omni-competence of mechanical causes and of mechanical explanations; they counted as telling arguments against those who would deny mechanism (Boyle 1772, 1: "Defence against Linus," 159).

Nevertheless, looking at column $\mathrm{E}$, it is difficult to contend that the theory Boyle was testing did not take a form similar to what we understand by "Boyle's Law." Indeed, he said that the "hypothesis" he set out to assess was that "the greater the weight that leans upon the air, the more forcible is its endeavour of dilatation, and consequently its power of resistance" (Boyle 1772, 1: "Defence against Linus," 156). So let us concede what we might actually dispute, that this hypothesis counts as an adequate verbal translation of our eponymous mathematically expressed law. ${ }^{20}$ The question is: did Boyle in fact conclude that evidence confirmed theory, and that this theory had legitimate standing as a law of nature?

Aspects of what Boyle concluded lead one to the view that he did maintain that $D$ confirmed E. He said:

Now although we deny not, but that in our table some particulars do not so exactly answer to what our formerly mentioned hypothesis might perchance invite the reader to expect; yet the variations are not so considerable, but that they may probably enough be ascribed to some such want of exactness as in such nice experiments is scarce avoidable.

Thus, the reader is invited to see D "fitting" E. But the passage continues to a further conclusion:

But for all that, till further trial hath more clearly informed me, I shall not venture to determine, whether or no the intimated theory will hold universally and precisely.... (Boyle 1772, 1: "Defence against Linus," 159.) ${ }^{21}$

The "further trials" Boyle alluded to were, so far as we know, never made, and, therefore, an accurate reading of what Boyle concluded does not allow us to ascribe "Boyle's Law" to him. He did not conclude that his findings confirmed any such lawlike statement; indeed, it is worth noting that he did not refer to his hypothesis as a law, even one whose entitlement to that designation was still to be determined. Dijksterhuis wrote that "Boyle did not assign to the law afterwards called 'Boyle's Law' its true significance as the first quantitative relation in the field of the physics of gases" $(1961,457$; cf. Dugas and Costabel 1964, 251). Putting the evaluation and the anachronism to one side, one would want to say that Dijksterhuis was quite right.

The case I am making is, of course, meat and drink to a rational reconstructionist. But I wish to press the point. Boyle did not enunciate "Boyle's Law," and there are

It would be very desirable to have a study tracing the changes in representation of "Boyle's Law," cspecially if attention were given to the relations between representation, reference, connections with evidence, and status as law. Materials assessing the transit of "Boyle's Law" through the work of Newton, Danicl Bemoulli, Charles, Gay-Lussac, and into the late nineteenth century may be found in Brush 1983, csp. 17-18. 21-23, 26-31 et seq.

"Sce Mach 1960, 149: “... Boyle knew that the law did not hold exactly." 
several interesting reasons why he did not do so. These include (1) his conception of natural law and its status; (2) his notion of what was involved in experimental exactness, precision, and the techniques appropriate to the reporting of experimental results; and (3) his conception of the physical referents of possible lawlike statements or quantitative measures. Since the point at which I want to arrive is the identification and analysis of a form of life, I want to show the structural connections between these considerations. I want to display the textured patterns in which ontology was bound up with the conventions of philosophical behavior, the mobilization of assent within a community, and the boundaries of that community and its practices. This will be done briefly in the case of Boyle's work on air, and in more detail in the sections that follow.

\section{The Status of Natural Law}

In the same text against Linus in which Boyle produced his table relating pressure and volume, he read the Jesuit a lesson about the proper scope of natural philosophical discourse. "[O]ur controversy," Boyle said, "is not what God can do, but about what can be done by natural agents, not elevated above the sphere of nature." Boyle's hypothesis of the spring of the air "would need no other advantage" than that thereby "things are explicated by the ordinary course of nature, whereas in [Linus'] recourse must be had to miracles." The precise context of these strictures has to be stressed: Boyle repeatedly professed his belief in the reality of miracles, and, as he said of himself, "none is more willing to acknowledge and venerate Divine Omnipotence ..." (1772, 1: "Defence against Linus," 149). Boyle was here showing his adversary the proper boundaries of experimental culture and the relations between experimental and religious discourse. There are things that happen, entities that exist, that nevertheless have no legitimate place in experimental discourse.

In this connection it is important to bear in mind the exact status and interpretation of laws of nature. Such laws, in Boyle's view, did undeniably exist, but it was vital to both right religion and the practice of mechanical philosophy that they be conceived correctly. Firstly, Boyle cautioned against the "vulgar" conception of natural law as a "notional rule of acting according to the declared will of a superior." It was not only absurd and incorrect, but also dangerous, to say that matter obeyed natural law in the same manner that intelligent agents acted in accordance with civil law. Thus, while Boyle availed himself from time to time of the vocabulary of "natural law," he insisted upon a rigorous dissociation between his usage and any connotation of sentient matter:

And even if I sometimes scruple not to speak of the laws of motion and rest, that God has established among other things corporeal, and now and then, (for brevity's sake, or out of custom) to call them, as men are wont to do, the laws of 
nature; [I have] in due place declared, in what sense I understand and employ these expressions. (1772, 5: "A Free Inquiry," 170; cf. Ruby 1986.)

Secondly, Boyle developed a positive sense of natural law that did no violence either to correct matter-theory or to a proper appreciation of God's power of action. In his "Discourse of Things above Reason" Boyle identified our knowledge of the physical properties of bodies as belonging to the class of "contingent" as opposed to "necessary" truths. Human knowledge of those properties is in general reliable, but it is absolutely dependent upon God's will:

... physical properties are but limited ... being gathered from the settled phenomena of nature, and are liable to this limitation of exception, that they are true, where the irresistible power of God, or some other supernatural agent, is not interposed to alter the course of nature. $(1772,5: 462-63$.)

Our ability to apprehend and to write down natural laws, however they were to be expressed, was a function of those "settled phenomena" being allowed by God's omnipotence to continue in their course. In the appendix to "The Christian Virtuoso," Boyle emphasized that it was "unreasonable to deny" that God "who freely or arbitrarily established those laws [of nature], may, either by suspending, or altering them," cause such events to come to pass, including what we customarily call miracles, "as the ordinary course of nature would never produce" $(1772,6: 679-80)$. There were, therefore, two dangers implicated in writing down natural laws as part of experimental practice. Firstly, since miracles did happen and since the "ordinary course of nature" was from time to time altered, we would be inaccurate in intimating that such laws would, in Boyle's words, "hold universally and precisely." In commenting upon Descartes' laws of motion, Boyle suggested that these were proved on a "metaphysical" basis, proceeding from an unwarranted stress upon the divine immutability (1772, 5: "The High Veneration Man's Intellect Owes to God," 140; see also Klaaren 1977, 169). Secondly, looking beyond the boundaries of experimental practice, we would be making a move potentially damaging to right religion, for we would be utilizing a resource contingently associated with those deists and freethinkers who conceived God to be bound by the laws of which he himself was the author. ${ }^{2}$

In Boyle's view there was an ordinary course of nature, sustained by what was termed God's ordinary concourse. But there was also God's supreme will and God's extraordinary concourse. These two modes of God's relations to nature, and of how nature might run, provided the frame of reference in which it was proper to speak of our knowledge of natural laws. There is also a further consideration. As McGuire

2 Boyle 1772, 5: "A Free Inquiry"; and on Boyle, the deists, and the laws of nature, see Jacob 1977, esp. chap. 3; Jacob 1978; also Shapin and Schaffer 1985, 201-7. For Boyle and natural law, see Oakley 1984, 82-92; also Klaaren 1977, 164-76; and Dijksterhuis 1961, 442. It is telling that the Royal Society's antagonist Henry Stubbe attempted to associate them with the very position that Boyle and his associates disavowed: Stubbe 1670, 170-72: "if God Almighty be regulated by the ruler of Geometry, and mechanical motion in the management of this world, ... I cannot any way comprehend how God can do any miracles...." 
has shown, Boyle adhered to a nominalist ontology. What had real physical existence in nature were particulars: particular things, particular bodies, particular events. These particulars had no relational principles contained within themselves: such relations had to be imposed upon the particular existents from an external source. This being so, the proper modes of knowing natural relations were indicated. One could not know natural laws a priori since there were no intrinsic relations within natural phenomena. On the contrary, as McGuire says, "in order to understand relations applicable to phenomena, observation and experimental methods must be used, since regularity is external to them and imposed on them" (McGuire 1972, 528). ${ }^{23}$ In this way ontology legitimated an empirical, if not precisely an experimental, practice because it justified the mobilization of witnesses around particular phenomena. The world was simply not structured in such a way that a priori practices would tell one anything reliable about it. Thus, on the one hand, one required a proper conception of natural law as limited in scope and as subject to God's will. Our knowledge of such laws was rightly regarded as contingent, lacking the necessary quality of mathematical or metaphysical truths. And mathematical modes or representation might be thought inappropriate for the expression of natural laws so conceived. On the other hand, the legitimate search for natural regularities implied, for Boyle, the use of observational and experimental methods and the exclusion or limitation of rationalist practices. Therefore, strictures on the use of mathematical language and methods were implicated in Boyle's conceptions of what both the natural and the supernatural worlds were like. And the same strictures prescribed how the experimental philosopher was to go on.

\section{Mathematics and Mechanism}

Boyle's preferred ontological scheme was, of course, mechanical and corpuscular. This was the scheme that, according to Burtt, was implied by "the mathematical view." Yet nowhere in Boyle's actual experimental practice or its reporting was this merger between mathematical methods and mechanical conceptions realized. What was in principle possible (and, according to some, logically entailed) was in practice avoided. Boyle's disinclination to merge mechanism and mathematicism seems strange, not just to modern eyes but also in light of the language used to express his own theory of matter. First in "The Sceptical Chymist" (1661) and later in "The Origin of Forms and Qualities" (1666) Boyle developed his matter theory. In the earlier text, Carneades (Boyle's mouthpiece in the dialogue form) thought it "not absurd to conceive" that the original creation divided a homogeneous "universal matter" into "little particles, of several sizes and shapes, variously moved." These particles were then "associated into minute masses or clusters" differentiated by the arrangement of their constituent parts (Boyle 1772, 1: "Sceptical Chymist," 474-75;

${ }^{23}$ See also Buck 1977, 67, for the nominalism of Graunt and Petty who "conceived the uses of mathematics in terms of creating order rather than discovering its immanent principles." 
see also Boas [Hall] 1952, 466). In "The Origin of Forms and Qualities" Boyle vastly expanded this theory, arguing that the qualities or properties of things are achieved "by virtue of the motion, size, figure, and contrivance of their own parts." New qualities are produced by "changing the texture [structure or arrangement] or motion" of constituent corpuscles $(1772,3: 13$; cf. ibid. "Usefulness of Mathematicks," 427; cf. Kuhn 1952, 17-18, 21-24).

This was a theory of matter which, it would seem, was ideally suited to producing physical explanations and accounts that were mathematical in form. One could specify the geometrical shapes of different corpuscles, identify their geometrical arrangements, quantify their states of motion. In practice, Boyle did none of these things. One might even wish to argue that, if doing so is what is involved in giving a mechanical explanation of properties, then Boyle never gave a mechanical explanation. As Dijksterhuis rightly says, Boyle's was "a program for the interpretation of nature rather than the interpretation itself. In fact, Boyle never attempts to determine what is the texture or the mixture of particular elements ... or compounds" (1961, 437; cf. ibid. 440). ${ }^{24}$ This conclusion applies as much to Boyle's pneumatics as it does to his chemistry. The air's spring, he announced, was a mechanical cause of phenomena and was itself in principle amenable to mechanical explanation. But he declined, even when pressed by adversaries like Hobbes, to specify those textures or states of motion of the air's corpuscles that accounted for elasticity. My "business," Boyle said, "is not ... to assign the adequate cause of the spring of the air, but only to manifest, that the air hath a spring, and to relate some of its effects" $(1772,1$ : "New Experiments Physico-Mechanical," 12) ${ }^{25}$ In this way, Boyle stipulated the terms in which the experimental philosopher was to frame his accounts, while pointing out the proper limits of those accounts.

A mathematical account of the actual textures and states of motion of specific bodies was not deemed necessary for the business of the experimental philosopher to proceed. In his "Proëmial Essay" of 1661, Boyle reckoned that explanations which reduced effects to "bulk, shape and motion" were indeed "the most satisfactory to the understanding," but at the same time he warned experimentalists not to "despise" those explanations of particular effects deduced from secondary qualities such as "heat, cold, weight, fluidity, hardness," and the like. The job of deducing these qualities from primary ones in particular instances was assigned, significantly, to another community of practitioners: "speculative wits, well versed in mathematical principles" (Boyle 1772, 1: "Proëmial Essay," 308; cf. Boas [Hall] 1952, 463 and note). Different communities terminated their explanatory chains at different conventionally agreed points, and this was right and proper.

\footnotetext{
* For revealing instances of Boyle's mechanical accounting for specific phenomena and the limits he placed on such accounts, see, for example, Boyle 1772, 4: "Of the Mechanical Origin of Heat and Cold," 236-59, esp. 239-40.244-46; ibid. 5: "Of the Reconcileableness of Specific Medicines to the Corpuscular Philsophy," 76-108, esp. 83-84, 108.

3 For Boyle's continuing adherence to causal nescience in the face of Hobbes' criticisms that such nescience disqualified him from the title of philosopher, see Shapin and Schaffer 1985, chap. 5, esp. 17885: also see Henry $1986,344-46$.
} 
The language of mechanism and corpuscularianism bound that ontology to experimental practice as the only sure way of knowing such a world. Agreement to deploy that language also excluded or restricted the role of mathematical accounting in experimental practice. The world upon which the experimental philosopher held himself to operate, and the world that was considered to dictate his proper referential talk, was one whose basic processes and ultimate constitutents were regarded as corresponding to the world of sensible phenomena. An experimental program that was predicated upon witnessed manipulations with sensible phenomena, whose permissible discourse was limited to those sensible phenomena, was taken to refer to an invisible world that was like the sensible world of tangible machines and billiard balls in motion. This is what, in Boyle's view, made the corpuscular philosophy "intelligible" and what recommended it over Scholastic doctrines of "forms" (Boas Hall 1978, 88, 91; cf. Kuhn 1952, 19-20; Harré 1970, 265). Using our ordinary sensory competences and experiences, we are assured that we can reliably conceive such a world. And we are instructed that conceivability is rightly to be expected of proper natural knowledge. To conceive the Scholastic or the Hermetic world, we must, according to Boyle, enter a practice in which our common empirical experiences are denied or set aside. This requirement is sufficient testimony to the unfoundedness of those practices (see, e.g., Dijksterhuis 1961, 437). The experimental philosopher operates in a visible realm, confident that its invisible basis belongs to the same kind of order. The aim of experiment is not then to offer detailed mechanical and corpuscular accounts of specific processes; its role is rather to show the compatibility between experimental findings and the principles of mechanism and corpuscularianism. ${ }^{26}$ Confidence in the essential similarity between the invisible domain and the sensible world of experiment is what allows and encourages the experimental philosopher to go on. He does not need to offer specific mathematical accounts of particular bodies or events in that invisible realm, and indeed he who does so runs the risk of subjecting the visible to the invisible, the readily intelligible and conceivable to the less intelligible and the esoteric, the concrete to the abstract. Boyle's experimentalism was to be a science of the concrete and the particular; mathematics was understood to be the formal study of the abstract and the universal.

\section{Mathematics and Access to the Experimental Community}

Boyle understood mathematics to encompass abstract and esoteric forms of culture, and, to that extent, he recognized sources of serious conflict between its deployment

${ }^{26}$ See the actual experimental narratives, as opposed to the conceptual setting, of Boyle's "Origin of Forms and Qualities" (1772, 3:1-112). On the general problem of "transdiction" (the justification of beliefs about the ultimate constituents of the world with reference to the role of experience in human knowledge), see Mandelbaum 1964, 61-62, 91, 95, 102, 111. On Boyle's "in-principle" mechanical explanation, see Gabbey 1985, 10ff.; Kargon 1971, 74-75. 
and the practice of experiment. The two cultural forms exhibited divergent procedures for regulating access to their communities and for defining who was competent to participate. In the sixteenth century, Copernicus identified the audience that was capable of assessing his work: "mathematics," he said, "is written for mathematicians." Thomas Kuhn, in his essay on the relative roles of mathematical and experimental traditions in the Scientific Revolution, noted that it was only the nonexperimental mathematical sciences that were characterized, even in antiquity, "by vocabularies and techniques inaccessible to laymen and thus by bodies of literature directed exclusively to practitioners" (Kuhn 1977a, 36, 39; cf. Mahoney 1984).

Boyle repeatedly remarked upon the relative inaccessibility of mathematics. ${ }^{27}$ To speak mathematical language was, in his view, to restrict the potential size of one's audience. On that basis alone the choice of a language appropriate to experiment was indicated. There is scarcely an experimental tract by Boyle that does not contain an apology for what he called his "prolixity." It was a style of experimental narrative that he considered to be abundantly justified.

I have noted that the purpose of such prose was to make experimental scenes vivid in the reader's mind and to make it morally warrantable to conclude that the experimental performances recounted had really been performed. Such linguistic practices were also justified because these accounts were said to be more intelligible and accessible to a wider audience than were alternative styles of communication. In "Hydrostatical Paradoxes" of 1666 Boyle claimed that he could have reported his findings in more formal and abstract mathematical language, but had chosen not to: "[T]hose who are not used to read mathematical books, are wont to be so indisposed to apprehend things, that must be explicated by schemes [i.e., diagrams]; and I have found the generality of learned men, and even of these new philosophers, that are not skilled in mathematicks," so unacquainted with hydrostatical theorems that a more expansive linguistic style was necessary. Ideas of this sort could not "be thoroughly understood without such a clear explication of [these] theorems, as, to a person not versed in mathematical writings, could scarce be satisfactorily delivered in a few words." Thus, many words had to be used. It was, Boyle said, "out of choice, that I declin'd that close and concise way of writing." He was writing not "to credit myself, but to instruct others," and, for that reason, "I had rather geometricians should not commend the shortness of my proofs, than that those other readers, whom I chiefly designed to gratify, should not thoroughly apprehend the meaning of them" $(1772,2: 740-41) .^{28}$

7f Cerscal's views on the relative accessibility and intelligibility of geometry versus algebra, in Koyré 1968.133 -34; in the seventeenth century, says Koyre, "it was algebra, especially algebraic geometry, that was different, unusual, incomprehensible." Pascal, preferring that natural philosophy be conceivable, opted for geometrical representation over the purity of algebra favored by Descartes and Leibniz. Also see Mahoncy 1980.

According to one of Boyle's eighteenth-century biographers, "He endeavours to make all the things he treats of, plain, easy, and familiar. There is no deep knowledge in mathematics, or algebra, previously required to understand him fully..." (Shaw 1738a, 1:xiv). 
Again, in his "Medicina Hydrostatica," Boyle argued the propriety of his choice of a nonmathematical language for experiment: “... I have not cast a treatise, about a subject wherein mechanics are so much employed, into the form of propositions, and given it a more mathematical dress." Had he done so, he claimed that he ran the risk of "discouraging those many, who, when they meet with a book, or writing, wherein the titles of theorem, problem, and other terms of art, are conspicuously placed, use to be frighted at them; and, thinking them to be written only for mathematical readers, despair of understanding it; and therefore lay it aside, as not meant for the use of such as they." And in the "Origin of Forms," Boyle indicted the logical "niceties" of Scholastic texts, which had the effect of making it "very difficult for any reader of but an ordinary capacity to understand what they mean ..." $(1772,5$ : "Medicina Hydrostatica," 454; ibid. 3: "Origin of Forms," 4-5). Evidently, the leveling of men's wits in natural philosophy was hardly to be attained by the continued use of mathematical language.

It was undeniable that mathematical language did have certain advantages. It was, for example, concise, economical, and, within its competent culture, clear. But this very conciseness of expression made mathematical language unclear to those who were not already competent users of that language. Mersenne, in Boyle's opinion, "affecting brevity, hath made himself obscure; so what he writes can scarce be understood, but by mathematical perusers." He wrote "more briefly than clearly." Since Boyle aimed to mobilize a wider audience than Father Mersenne, he would translate the latter's concise but exclusive mathematical language into prolix but accessible form. Boyle said that he wanted to speak to "chemists, apothecaries, lapidaries, physicians, and diverse other experimenters," and not merely to the educated elite (1772, 5: "Medicina Hydrostatica," 473; cf. Shaw 1738a, 1:xiii; Boas [Hall] 1958, 34, 207). Thus, he had to ensure that everyday language and the language of the experimental community substantially overlapped. As Schaffer and I have shown elsewhere, Boyle's concern for this wider audience was constitutive of his program for the generation and validation of the category of the experimental matter of fact. Such facts were to count as the secure foundation of proper experimental discourse, and they were to be produced by mobilizing a witnessing community that included in principle any person of normal perceptual competence and suitable moral probity. Exclusive modes of communication were incompatible with both the moral and the epistemological nature of the experimental form of life. ${ }^{29}$

\section{Reason, Mathematics, and Real Experiments}

In the experimental form of life, the practice of producing true knowledge was deemed to be totally dependent upon collective labor. Real experiments had to be performed, seen, and believed to be performed, by a witnessing community. The

${ }^{29}$ See Shapin and Schaffer 1985, chaps. 2, 5, and esp. p. 218 for the rejection of testimony from persons of suspect perceptual and moral reliability. 
ultimate warrant for experimental knowledge was not to be the mind but the eye, not the authority of any individual but the belief of the collective. Its final authority was to be not human but natural. What is seen, and what is assented to by us all, is what is. For these reasons the notion of ideal experiments was anathema. No experiment could carry conviction unless there was adequate assurance that it had actually been done.

During the 1660s Boyle developed his critique of what are now termed "thought experiments" and of the culture in which such practices were considered legitimate or even superior to a program of actual experimentation. His specific targets included Hobbes, Spinoza, and Pascal. Each of these, in various ways, maintained that rationalist methods, including mathematical and logical techniques, were valid alternatives to Boyle's experimental program. ${ }^{30}$ In 1664 Boyle was requested by the Royal Society to report upon a series of hydrostatical experiments communicated by Pascal. In one instance, Boyle expressed doubt that Pascal ever "actually made the experiment" he reported, and, in the case of an experiment whose successful performance required a man to sit 20 feet under water holding a cupping glass to his leg, most modern commentators are disposed to agree with Boyle (Boyle 1772, 2: "Hydrostatical Paradoxes," 758; cf. ibid. 746). ${ }^{31}$ In Boyle's judgment, Pascal "thought he might safely set [the experimental result] down, it being very consequent to those principles of whose truth he was fully persuaded." For Pascal it seemed to be enough that he had a "just confidence" that he was not "mistaken in his ratiocination." Boyle cautioned his readers not to credit "experiments that are but speculatively true," because these "may oftentimes fail in practice." What was necessarily true in one practice might not be true at all in another (ibid. 758, 745-46, 759).

Boyle's exchanges with Spinoza, mediated by Henry Oldenburg, took a similar form. In 1661 Spinoza had sent Oldenburg proofs of his theory of matter "made in a geometrical manner" (Spinoza to Oldenburg, September 1661, in Hall and Boas Hall 1965-86, 1:424-28, on 427). ${ }^{32}$ Oldenburg initially applauded the rationalist's way of going on ("I warmly approve your geometric method of proof," Oldenburg to Spinoza, 17 September 1661, in Hall and Boas Hall 1965-86, 1:430), but he soon adopted a more judicious role as Boyle's mouthpiece, sending Spinoza Boyle's Certain Physiological Essays of 1661 and attempting to explain the Royal Society's view of experimental practice. Spinoza was not persuaded, and he did not concede that Boyle's methods were in principle capable of persuading. There was, in Spinoza's view, a fundamental contrast between experiment and mathematics in their

"Hobbes' objections to Boyle's experimental program are treated in full in Shapin and Schaffer 1985, esp. chap. 4, and will not be dealt with here. However, it is important to note that Hobbes held up gcometry as a model for proper natural philosophy.

$"$ For modern accounts of Pascal's "experiments" and their status, see Kuhn 1977a, 44-45; Conant $1970 \mathrm{a}, 59-60$ (both of whom support Boyle's judgments and share his sense of the necessity of actual experimentation). For a modern rationalist view, see Koyré 1968a, esp. 148-52. Koyré does not want to conclude that Pascal did not do the experiments (despite problems with impossible glassware), only that he did not describe them as done: “. .. Pascal has not given us a complete and exact account of the experiments that he made or imagined" (my emphasis). See also Dear 1987 and, for the classic Galilean research site, see, for example, Naylor 1976.

Fot an account of these exchanges, see Hall and Boas Hall 1964. Cf. Shapin and Schaffer 1985, 253. 
respective abilities to secure conviction: "Since Mr. Boyle does not put forward his proofs as mathematical, there will be no need to enquire whether they are altogether convincing." Boyle's experiments were simply "superfluous"; their alleged products could be arrived at more expeditiously and established more surely through the exercise of pure reason. Discussing Boyle's doctrine of fluidity, Spinoza judged that "One will never be able to prove this by chemical or other experiments, but only by reason and calculation" (Spinoza to Oldenburg, April 1662, in Hall and Boas Hall 1965-86, 1:462; cf. Boas Hall 1978, 86). Oldenburg was instructed to reply that "Our Boyle is one of those who are distrustful enough of their reasoning to wish that the phenomena should agree with it" (Oldenburg to Spinoza, 3 April 1663, in Hall and Boas Hall 1965-86, 2:42). Reasoning by itself established nothing within the experimental program. "Wary naturalists" were right to "consult sense about those things, that fall under the cognisance of it" in order to check "whether men have not been mistaken in their hypotheses and reasonings...." To such modest men it must be "of great satisfaction to find the things, that are taught them, verified by the visible testimony of nature herself" (Boyle 1772, 2: "Hydrostatical Paradoxes," 742; cf. 740).

\section{Certainty and Accuracy in Mathematical and Experimental Practice}

Mathematical and logical practice, on the one hand, and experimental practice, on the other, each carried with it its proper grade of certainty and means of securing assent. In Boyle's view, these practices, while legitimate within their proper domains, were incompatible. Pascal's "just confidence" was a confidence unwarranted by authentic experimental conduct. One could not and should not expect of real physical experiment what one might legitimately expect of geometry and logic. In his 1661 essay on unsuccessful experiments, Boyle lectured mathematicians on the inappropriateness of their canons to the actual explication of real physical bodies and processes. It was, he said, the "privilege and glory" of "mathematical writers" to "affirm nothing, but what they can prove by no less than demonstration." Yet such mathematicians were apt to err when they moved from their abstract domain to the natural world as it actually was:

the certainty and accurateness, which is attributed to what they deliver, must be restrained to what they teach concerning those purely mathematical disciplines, arithmetic and geometry, where the affections of quantity are abstractedly considered: but we must not expect from mathematicians the same accurateness, when they deliver observations concerning such things, wherein it is not only quantity and figure, but matter and its other affections that must be considered (Boyle 1772, 1: "Two Essays, Concerning the Unsuccessfulness of Experiments," 347). ${ }^{33}$

${ }_{33}$ This appears to be a liberal paraphrase of Aristotle's Metaphysics, 995a 15: "The minute accuracy of mathematics is not to be demanded in all cases, but only in the case of things which have no matter." 
In "Hydrostatical Paradoxes," Boyle recognized that some of his readers "will not like, that I should offer for proofs such physical experiments, as do not always demonstrate the things, they would evince, with a mathematical certainty and accurateness." Nevertheless, he insisted that "in physical enquiries it is often sufficient, that our determinations come very near the matter, though they fall short of a mathematical exactness. ..." There was absolutely no reason to apologize for using expressions that might appear to mathematicians "not positive and determinate enough to be employed about matters, to which mathematical demonstrations are thought applicable" (1772, 2:741).

There were two main reasons why experimental imprecision was to be expected and why it was to be accepted. Firstly, real experimental measurements were contingently imprecise because of the imprecision of the measuring instruments we actually possess. Actual, as opposed to ideal, experiments were endemically liable to troubles arising from instrumental sources. In his 1685 essay on the determination of the specific gravity of mineral waters, Boyle acknowledged that better weighing instruments than he had available were necessary "to discover such minute differences" as he was concerned with. The balances to be found "in some apothecary's or other tradesman's shop" were almost always imprecise, sometimes very significantly so (1772, 4: "Natural Experimental History of Mineral Waters," 810; ibid., 5: "The General History of Air," 810; cf. Boas [Hall] 1958, 215-16, 219-22; Stock 1969). Importantly, this very contingent imprecision that Boyle lamented was also turned to the advantage of the experimental program. Once we recognized what standards of accuracy were actually appropriate, we would not expect from experimental inquiry that which was unreasonable, and we would be put in a position properly to evaluate the credibility of metrological testimony. Reports of measurements that were too precise might be rightly suspected. Contrarily, we should not rush to reject measurements which deviated from expectation or theory. Instrumental inaccuracy might offer a suitable excuse for apparent failure to confirm theory or to achieve replication. ${ }^{34}$

In "Medicina Hydrostatica," Boyle said that he did not "pretend (and indeed it is not necessary) that the proportion, obtainable by our method, should have a mathcmatical preciseness. For in experiments where we are to deal with gross matter, and to employ about it mathematical instruments, it is sufficient to have a physical, and almost impossible to obtain (unless sometimes by accident) a mathematical exactness" (1772, 5:480). Boyle thus stipulated an error factor as belonging to genuine experimental inquiry contingently but inescapably. We cannot imagine that our frailties and our instrumental inadequacies can ever be surmounted. The experimentalist thus assumed a moral obligation to recognize that fact in his evaluations and in his communications. The public recognition of this contingent inaccuracy could count as a sign that one was speaking the authentic language of experiment, rather

- On precision and the following of written recipes, see Eamon 1984, 127-28; for problems attending experimental replication in general, see Shapin and Schaffer 1985, chap. 6; and Collins 1985, chap. 4. 
than the incompatible language of mathematics, logics, or metaphysics. A report of an air-pump almost devoid of atmospheric air gave the tokens of experimental authenticity in a way which a report of an absolute vacuum did not. A report of a manometric gauge whose level descended almost to the bottom of the tube offered the signs of credibility which a report of total subsidence failed to do. The metrological world that Boyle recommended was one inhabited by honest men, sincerely delivering testimony of what they had witnessed using real and fallible physical instruments, in concrete experimental situations. The relevant contrast was with the ideal world of the mathematician.

There was a second major reason why mathematical precision was not to be expected from, and why mathematical methods were inappropriate to, a program of real experimentation. This reason flowed from views of the underlying nature of the physical world with which experiment dealt. Boyle's experimental world was held to be ontologically different from the world presupposed by mathematicians. As Marie Boas [Hall] noticed thirty years ago, Boyle did not contend that physical qualities were uniform. Indeed, he maintained that they might vary with circumstance (Boas [Hall] 1958, 216)..$^{35}$ "In doing so," she said, "he rejected the mathematical and ideal world of the more Platonic-minded mathematicians among his contemporaries ..." (ibid.) ${ }^{36}$ Hall's insight deserves to be extended and refined. For one thing, Boyle was centrally concerned with the practical chemical problem of ascertaining the purity of the materials used by the chemist, the apothecary, the physician, and the assayer of ores and minerals. The lack of agreed standards for the composition of substances was a serious problem. It was a problem, of course, for practical chemistry and medicine, but it was also a source of serious trouble for the program of experimental replication that Boyle was encouraging. How could a replicator know that he had repeated "the same" experiment, that his results were rightly comparable with those of another experimenter, if he could not be sure that he had employed "the same" substances? ${ }^{37}$

Boyle's rejection of the ontology of the ideal reached further than this. He also held that substances which were rightly designated as "the same" might and did vary in their physical properties. For this reason, measurements made upon them were inherently lacking in mathematical precision. In this case, it was not the fault of our instruments, nor of ourselves, nor even, in a strict sense, of the complexities of real physical situations that accounted for variation and imprecision in experimental

\footnotetext{
${ }^{35}$ However, she draws back from a full appreciation of this insight. To her, Boyle's position was an "unfortunate conviction," a defect in his otherwise praiseworthy experimental practice.

${ }^{36}$ Of course, the modern culture of mathematics and modern understandings of its application to natural knowledge encompass non-Platonic conceptions, for example, probabilistic and statistical views of natural law and their representation. However, Boyle's rejection of mathematics proceeded partly from a strong identification between mathematics and Platonism. On mathematical Platonism, see Koyré 1968b, chap. 2.

${ }^{37}$ For Boyle's views on the problems attending "sophisticated" and variable materials, see Boyle 1772, 1: "Unsuccessfulness of Experiments," 319-33. And for a revealing experimental episode in which such variation was practically used to account for failure to replicate, see Henry Oldenburg to Francisco Travagino, 11 October 1675, in Hall and Boas Hall 1965-86, 12:10.
} 
measurements. It was reality that was responsible. A reality so structured was one that spoke against the propriety and applicability of mathematical representations and mathematicians' canons of accuracy and exactness.

It is reasonably well known that Boyle thought that substances like air and water varied in their physical properties from one locale to another and from one time to another. Consider the substance "air," whose physical properties Boyle studied experimentally from the late 1650 s until the end of his life and which was the proper referent of his "law" of spring. Boyle, like most of his contemporary mechanical philosophers, took atmospheric air to be a complex mixture. "[B]y air," he said, "I understand not, (as the Peripateticks are wont to do) a mere elementary body...." "There is scarce a more heterogeneous body in the world." The air was "that great receptacle or rendesvous of celestial and terrestrial effluviums," of "innumerable seminal corpuscles, and other analogous particles..." (Boyle 1772, 4: "Some Hidden Qualities in the Air," 85, 91; see also ibid., 1: "An Examen of Hobbes," 196; ibid., 5: "The General History of the Air," 612-15; and Shapin and Schaffer 1985, 178-85 [for disputes between Boyle and Hobbes involving the composition of the air]). Its precise composition at any place and time depended upon the nature and quantity of effluvia it was receiving from the bowels of the earth and from celestial bodies. And its physical properties, including its elasticity, thus also depended upon its momentary composition. In Boyle's view there was a fraction of atmospheric air (which might be called "pure air" and distinguished from various effluvia) that uniquely possessed the characteristic of springiness: “... I have not observed any one attribute, that I think to be so much the property of air, and so fit to distinguish its true particles from aqueous vapours, earthy exhalations, and the effuvia of other bodies, as a durable elasticity or springiness" (1772, 5: "The General History of the Air," 618; ibid., 4: "Some Hidden Qualities in the Air," 90). But the elasticity of any specific instance of atmospheric air flowed from the quantity of this pure air it contained and from the effect on this pure air of various inelastic (or variably elastic) effluvial admixtures. Boyle, for example, speculated on the effect of sun spots upon the gravity of atmospheric air (1772, 4: "Some Hidden Qualities in the Air," 95). And in his original series of pneumatic experiments he theorized that discrepancies between English and continental findings might be due to the fact that English air was "grosser" (i.e., contained more terrestrial effluvia) than French air (1772, 1: "New Experiments Physico-Mechanical," 38). We can perhaps now understand why, in enunciating his law of spring, Boyle said that he was unwilling to determine whether that theory "will hold universally and precisely" (ibid.: "Defence against Linus," 159). It was only to be expected that different instances of air would exhibit different clasticities.

In the 1690 "Medicina Hydrostatica," Boyle worked up methods for determining with great accuracy the specific gravities of a range of substances. He encountered practical problems in obtaining the same results when using various instances of given substances. For example, in measurements of the specific gravity of rock crystal (which 
Table 2. A table of specific gravities

\begin{tabular}{ll}
\hline Substance & Specific Gravity* \\
\hline Bezoar-stone & $148 / 100$ \\
A piece of the same & $164 / 100$ \\
A fine oriental one & $153 / 100$ \\
Another & $1^{34 / 100}$ \\
Lapis manati & $286 / 100$ \\
Another of the same & $2^{29 / 100}$ \\
Another from Jamaica & $2^{27 / 100}$ \\
Marcasites & $4^{45 / 100}$ \\
Another from Stalbridge & $4 \frac{1 / 2}{}$ \\
Another more shining than ordinary & $478 / 100$ \\
Talc $\left\{\begin{array}{l}\text { Venetian } \\
\text { Jamaican }\end{array}\right.$ & $2^{73 / 100}$ \\
\hline
\end{tabular}

${ }^{*}$ Expressed as the proportion of weight in air to weight in water.

Excerpted from Boyle 1772, 5:505-7.

was something of a standard for Boyle), he got differing values. He concluded in this case that "it is not improbable, that different pieces of rock-crystal itself, though of equal bulk, may not be precisely equal in ponderosity ..." (1772, 5:456). Lodestones from different countries differed in their specific gravities; "Spanish mercury," which is "counted the richest," differed from "common quicksilver"; and Boyle "did not find all running mercuries, though they did not appear adulterated, to be precisely the same weight ..." (ibid., 467-68 [my emphasis]). ${ }^{38}$ In the following tract entitled "A Previous Hydrostatical Way of Estimating Ores," Boyle produced a large number of specific gravity determinations in tabular form. For a number of substances Boyle's table gave a range of values. In the excerpts shown in Table 2 we see four specific gravity values for bezoar stone (a calculus found in the guts of ruminants), three for lapis manati (presumably a stone associated with the cetacean), three for marcasites (copper or iron pyrites) and two for talc (Boyle 1772, 5:489-507). ${ }^{39}$

In some cases it is indeed evident that Boyle ascribed such variation to differences in purity, but in others it is quite clear that the discrepancies were taken as an accurate reflection of natural variations in "the same" substances. It was not, in these instances, a matter of impurity, nor of adulteration, nor of real variations in metrological procedures. Instead, it was the right outcome of metrological techniques when brought to bear upon a particularistic reality. And Boyle made this point

38 For Boyle's work on adulteration and this text, see Stieb 1964.

39 For Boyle's notes on these measurements, see Royal Society, Boyle Papers, Commonplace Book 189, fols. 151-52. 
abundantly plain when commenting upon discrepancies between his values and those obtained by other practitioners. Such variation "may," he said, "very probably be imputed to that variety of texture and compactness, that may be found in several bodies of the same kind or denomination, neither nature nor art being wont to give all the productions, that bear the same name, a mathematical preciseness, either in gravity or in other qualities" (1772, 5: "Previous Hydrostatical Way," 505 [my emphasis]). ${ }^{40}$

\section{The Real, the Ideal, and the Moral Community}

The language of mathematics was taken to be an abstract language referring to an ideal world. Boyle denied that such a world actually existed. Men could, if they chose, construct such idealizations, but to do so would be to engage in a practice that was both illegitimate and immoral. It was immoral because idealization erected a bogus and an inadequate authority for scientific statements. Instead of "the visible testimony of nature" we should have the authority of men and their cultural constructs. As Marie Boas [Hall] says, "Boyle preferred to deal experimentally with the world as he found it" $(1958,216)$. This presupposes a view of how the world actually presented itself to a specified community with given capacities, expectations, purposes, and cultural inheritance. Boyle pointed to a community for whom the world presented itself as a set of phenomenal particulars. He assured this community that the world was indeed ultimately composed of particulars. The community's representations ought to be aligned with its ontology. They ought not to be abstracted from such a world; they ought to reflect that world's real underlying structure. Transdiction from the visible to the invisible, from the phenomenal to the real, was not, for Boyle, a move from one sort of world to another. His mechanistic and corpuscularian ontology testified that the invisible world was, indeed, of the same sort as the phenomenal world.

Charles Gillispie has written that "there is, after all, an arrogance in mathematics, originating in the mind and not in nature" $(1960,109)$. Gillispie's sense of mathematical hubris seems to stem from the same roots as Boyle's. The moral order of mathematical abstraction and idealization is taken to be different in kind from the moral order of empirical practice. Mathematical authority is considered to subject the eye and the hand to the mind, appearances to conceptions. Mathematical certainty binds men's will: the price of the highest certainty is the sacrifice of volitional action in giving assent. ${ }^{41}$ And the cost of access to the mathematical

- Boyle compared some of his specific gravity values with those obtained previously by Bacon 1857-58, 5:341-42. See Royal Society, Boyle Papers, Commonplace Book 189, fols. 3-4, where Boyle noted Bacon's observation that these values differed in the "same species or denomination some being heavier than others, and $y^{\prime}$ therefore there is some contingency in this affair; so that 'tis not necessary $y^{t}$ the Individuals he made his tryals $\mathrm{w}^{\text {th }}$, should be exact standards of the nature of their respective species, or should ... agree altogether to a Tittle wth Expts. of other men." For Michael Faraday's strikingly similar rejection of mathematics on ontological grounds, see Cantor 1985, esp. 78.

"See the perceptive treatment of demonstrative versus empirical modes of exposition and their encapsulation of different moral orders in Anderson 1984, 42-43. 
community is surrendering the value placed upon commonsense apperceptions of how the world seems to be. Ernan McMullin has recently written about the suppositions involved in mathematical idealization. Such idealization, McMullin notes, "leaves aside the qualitative detail that constitutes the physical singular as singular." "Mathematical idealization is a matter of imposing a mathematical formalism on a physical situation, in the hope that the essentials of that situation ... will lend themselves to mathematical representation." Such idealization gives us, as McMullin says, "a defining characteristic of the new science" $(1985,249,254-55)$.

Of course, there is also a long tradition of scientific reactions against mathematical idealization and abstraction. It goes back to Aristotle; in the early eighteenth century it took in the anti-Newtonian divine John Hutchinson; in the middle of the century it was expressed by Buffon, and in the late eighteenth century by the radical Jacobins; in the nineteenth century Michael Faraday objected to the "tyranny" of mathematics as did William Bateson in the twentieth century. Twentieth-century philosophical opponents of mathematical idealization include Husserl and Nancy Cartwright. ${ }^{42}$ In Galileo's Two New Sciences Salviati concedes that "the imperfections of matter [are] capable of contaminating the purest mathematical demonstrations." But what counted as a "contamination" to Salviati was for Boyle an expression of the real language of Nature's Book. ${ }^{43}$

I started with the metaphor of Nature's Book and the language in which it was deemed to be written. I used this well-known image to introduce the notion of the language game and the form of life in which the game is embedded. I have examined an episode in which a decision was being considered about which language a community ought to speak, and I have tried to display the range of elements implicated in that decision. I have dealt with recommendations about representational conventions, with the community's sense of what reality is like, and with the patterning of social relations; and I have pointed to the role of linguistic practices in each of these. I have attempted to show that it is necessary to deal with these elements as part of a structure. The structure is held together using linguistic practice, but the force that binds it is a moral force. A decision to use a given language involves moral deliberation, and the stable use of language by a community is cemented by moral bonds. Moral considerations are implicated in several ways. Firstly, a language embeds the source of legitimate authority for its speaking: we speak this way because that is the way the world is. Secondly, a language incorporates techniques for securing its user's assent; it points to the arena in which volitional action, belief, demands for intelligibility and the like, are properly deployed, and to the limits rightly set on justifications of assent. Thirdly, a language signals the community's boundaries and its relations with other communities. It in dicates who

42 Cantor 1985a, for Faraday; Sloan 1976, for Buffon and his debt to Locke; Coleman 1970; Hus erl 1970; Garrison 1986; Cartwright 1983, who professes "an Aristotelian belief in the richness and varisty of the concrete and particular" (p. 19); Kingsland 1986; McMullin 1985, esp. 247-53, 271-73.

${ }_{43}$ Galileo 1933, 2 (although I use here the translation of McMullin 1985, 251); see also Galileo 1953, 216, where Simplicio tells Salviati that "mathematical subtleties are true in the abstract, but applied to sensible physical matter they do not hold good." 
may belong and on what terms, and it exhibits the limits beyond which one is not to go if continued membership is wished.

The moral force that holds the structure together ultimately becomes invisible. We account for our language by saying that it flows from reality, even as we construct our versions of reality using linguistic resources. What slips away from our grasp is what is directly in front of us. This is the community's practical life, its way of doing things, including its linguistic activities. It is this practical life that ties our representations to reality and the same practical life provides the final moral warrant for doing so.

\section{Acknowledgments}

I gratefully acknowledge comments on an earlier version of this paper by Peter Dear and Simon Schaffer. Talks deriving from this material were given at the Center for the History and Philosophy of Science at Johns Hopkins University and at the Division of the History of Science at Leeds University. This paper has benefitted from criticism by members of those audiences, particularly Geoffrey Cantor, Michael Dennis, Owen Hannaway, and Michael Heyd. For permission to quote from the Boyle Papers I thank the Council of the Royal Society of London.

\section{References}

Agassi, Joseph, 1977. "Who Discovered Boyle's Law?" Studies in History and Philosophy of Science 8: 189-250.

Alexander, Peter, 1985. Ideas, Qualities and Corpuscles: Locke and Boyle on the External World. Cambridge: Cambridge University Press.

Anderson, Wilda C., 1984. Between the Library and the Laboratory: The Language of Chemistry in Eighteenth-Century France. Baltimore: Johns Hopkins University Press.

Bacon, Francis, 1857-58."The History of Dense and Rare," in The Philosophical Works of Francis Bacon, ed. James Spedding, Robert Leslie Ellis, and Douglas Denon Heath, 5 vols. London, 5: 338-400.

Bennett, J. A., 1982. The Mathematical Science of Christopher Wren. Cambridge: Cambridge University Press.

Birch, Thomas, 1772. "The Life of the Honourable Robert Boyle," in Boyle 1772, 1: vi-clxxi.

Bloor, David, 1983. Wittgenstein: A Social Theory of Knowledge. London: Macmillan.

Boas [Hall]. Marie, 1952. "The Establishment of the Mechanical Philosophy," Osiris 10: $412-541$.

Cambridge University Press. 
1959. "Structure of Matter and Chemical Theory in the Seventeenth and Eighteenth Centuries," in Clagett 1959, 499-514.

Bods Hall, Marie, 1978. "Matter in Seventeenth-Century Science," in McMullin 1978, 76-99.

Bochner, Salomon, 1966.The Role of Mathematics in the Rise of Science. Princeton:

Princeton University Press.

Boyle, Robert, 1772. The Works, ed. Thomas Birch, 6 vols. London.

Tractates from Boyle 1772 cited in the paper:

Excerpts from "Considerations on the Style of the Scriptures," 1: xlix.

"New Experiments Physico-Mechanical, touching the Spring of the Air and its Effects," 1: 1-117.

"A Defence of the Doctrine touching the Spring and Weight of the Air ... against the

Objections of Franciscus Linus," 1: 118-85.

"An Examen of Mr. T. Hobbes His Dialogus Physicus de Natura Aëris," 1: 186-242.

"A Proëmial Essay ... with Some Considerations touching Experimental Essays in General," 1: 299-318.

"Two Essays, Concerning the Unsuccessfulness of Experiments," 1: 318-53.

"The Sceptical Chymist ..., ," 1: 458-586.

"Some Considerations Touching the Usefulness of Experimental Natural Philosophy," 2: 1-201.

"Hydrostatical Paradoxes, made out by New Experiments," 2: 738-97.

"The Origin of Forms and Qualities, According to the Corpuscular Philosophy," 3: $1-112$.

"Of the Usefulness of Mathematicks to Natural Philosophy. Or, that the Empire of

Man may be promoted by the Naturalist's Skill in Mathematicks, (as well pure, as mixed)," 3: 425-54; this is part of "Some Considerations Touching the Usefulness of Experimental Natural Philosophy ... The Second Tome," 3: 392-456.

"The Excellency of Theology, compared with Natural Philosophy," 4: 1-66. "About the Excellency and Grounds of the Mechanical Hypothesis," 4: 67-78.

"Suspicions about Some Hidden Qualities in the Air," 4: 85-96.

"Of the Mechanical Origin of Heat and Cold," 4: 236-59.

"A Discourse of Things above Reason ," 4: 406-69.

"A Continuation of New Experiments, Physico-Mechanical ... The Second Part," 4: 505-93.

"Short Memoirs for the Natural Experimental History of Mineral Waters," 4: 794821.

"Of the Reconcileableness of Specific Medicines to the Corpuscular Philosophy," 5: 76-108.

"Of the High Veneration Man's Intellect Owes to God, peculiarly for His Wisdom and Power," 5: 130-57.

"A Free Inquiry into the Vulgarly Received Notion of Nature," 5: 158-254.

"Medicina Hydrostatica: or, Hydrostatics Applied to the Materia Medica," 5: 45389. 
"A Previous Hydrostatical Way of Estimating Ores," 5: 489-507.

"The General History of the Air," 5: 609-743.

"Appendix to the First Part of the Christian Virtuoso," 6: 673-715.

"The Christian Virtuoso. The Second Part," 6: 717-96.

Brush, Stephen G., 1983. Statistical Physics and the Atomic Theory of Matter, from Boyle and Newton to Landau and Onsager. Princeton: Princeton University Press.

Buck, Peter, 1977. "Seventeenth-Century Political Arithmetic: Civil Strife and Vital Statistics," Isis 68: 67-84.

Burnet, Gilbert, 1742. Select Sermons ... and a Sermon at the Funeral of the Honourable Robert Boyle. Glasgow.

Burtt, E. A., 1954. The Metaphysical Foundations of Modern Physical Science, revised ed. Garden City, N.Y.: Doubleday Anchor Books.

Cantor, G. N., 1979. "Revelation and the Cyclical Cosmos of John Hutchinson," in Jordanova and Porter 1979, 3-22.

— , 1984. "Berkeley's The Analyst Revisited," Isis 75: 668-83.

- 1985. "Light and Enlightenment: An Exploration of Mid-Eighteenth-Century Modes of Discourse," in Lindberg and Cantor 1985, 67-106.

- 1985a. "Reading the Book of Nature: The Relation between Faraday's Religion and His Science," in Gooding and James 1985, 69-81.

Cartwright, Nancy, 1983. How the Laws of Physics Lie. Oxford: Clarendon Press.

Centore, F. F., 1970. Robert Hooke's Contributions to Mechanics: A Study in Seventeenth Century Natural Philosophy. The Hague: Nijhoff.

Clagett, Marshall, ed., 1959. Critical Problems in the History of Science. Madison:

University of Wisconsin Press.

Cohen, I. Bernard, 1980. The Newtonian Revolution. Cambridge: Cambridge University Press.

Coleman, William, 1970. "Bateson and Chromosomes: Conservative Thought in Science," Centaurus 15: 228-314.

Collins, H. M., 1985. Changing Order: Replication and Induction in Scientific Practice. London: Sage.

Conant, James Bryant, ed., 1970. Harvard Case Histories in Experimental Science, 2 vols. Cambridge, Mass.: Harvard University Press.

—, 1970a. "Robert Boyle's Experiments in Pneumatics," in Conant 1970, 1: 1-63.

Dear, Peter, 1985. "Totius in verba: Rhetoric and Authority in the Early Royal Society," Isis 76: 145-61.

- 1987. "Jesuit Mathematical Science and the Reconstitution of Experience in the Early Seventeenth Century," Studies in History and Philosophy of Science 18: 13375.

Dijkstcrhuis, E. J., 1961. The Mechanization of the World Picture, trans. C. Dikshoorn. Oxford: Clarendon Press.

Dillenberger, John, 1960. Protestant Thought and Natural Science: A Historical Study. Nashville, Tenn.: Abingdon Press. 
Drake, Stillman, See Galileo 1957.

— , 1985. "Galileo's Accuracy in Measuring Horizontal Projections," Annali dell' Istituto e Museo di Storia della Scienza di Firenze 10: 3-13.

Dugas, R. and P. Costabel, 1964. "The Birth of a New Science: Mechanics," in Taton 1964, 236-67.

Eamon, William, 1984. "Arcana Discovered: The Advent of Printing, the Books of Secrets Tradition and the Development of Experimental Science in the Sixteenth Century," History of Science 22: 111-50.

- , 1985. "Books of Secrets in Medieval and Early Modern Science," Sudhoffs Archiv 69: 26-49.

Eisenstein, Elizabeth L., 1980. The Printing Press as an Agent of Change: Communications and Cultural Transformations in Early-Modern Europe. Cambridge: Cambridge University Press.

Feingold, Mordechai, 1984. The Mathematicians' Apprenticeship: Science, Universities and Society in England, 1560-1640. Cambridge: Cambridge University Press.

Foucault, Michel, 1970. The Order of Things: An Archaeology of the Human Sciences. London: Tavistock.

Gabbey, Alan, 1985. "The Mechanical Philosophy and Its Problems: Mechanical Explanations, Impenetrability, and Perpetual Motion," in Pitt 1985, 9-98.

Galileo Galilei, 1933. Dialogues concerning Two New Sciences, trans. Henry Grew and Alfonso de Salvio. New York: Macmillan.

- 1953. Dialogue on the Great World Systems, ed. Giorgio de Santillana. Chicago: The University of Chicago Press.

-, 1957. Discoveries and Opinions of Galileo. trans. and ed. Stillman Drake. Garden City, N.Y.: Doubleday Anchor Books.

— , 1957. "The Assayer [excerpts]," in Galileo 1957, 217-80.

Garrison, James W., 1986. "Husserl, Galileo, and the Processes of Idealization," Synthese 66: 329-38.

Gascoigne, John, 1985. "The Universities and the Scientific Revolution: The Case of Newton and Restoration Cambridge," History of Science 23: 391-434.

Gaukroger, Stephen, ed., 1980. Descartes: Philosophy, Mathematics and Physics. Brighton: Harvester.

Gillispie, Charles Coulston, 1960. The Edge of Objectivity: An Essay in the History of Scientific Ideas. Princeton: Princeton University Press.

Glanvill, Joseph, 1661. The Vanity of Dogmatizing. London.

Golinski, Jan Victor, 1984. "Language, Method and Theory in British Chemical Discourse, c. 1660-1770." Unpubl. Ph.D. thesis. Leeds: University of Leeds. Gooding, David and Frank A. L. James, eds., 1985. Faraday Rediscovered: Essays on the Life and Work of Michael Faraday, 1791-1867. Basingstoke: Macmillan. Grosart, Alexander B., ed., 1887. The Lismore Papers, 2d series, 5 vols. London. Hacking, Ian, 1975. The Emergence of Probability: A Philosophical Study of Early Ideas about Probability, Induction and Statistical Inference. Cambridge: Cambridge University Press. 
Hall, A. Rupert and Marie Boas Hall, 1964. "Philosophy and Natural Philosophy:

Boyle and Spinoza," in Taton and Cohen 1964, 241-56.

- , eds., 1965-86. The Correspondence of Henry Oldenburg, 13 vols. Madison:

University of Wisconsin Press; London: Mansell; London: Taylor and Francis.

Hannaway, Owen, 1975. The Chemists and the Word: The Didactic Origins of

Chemistry. Baltimore: Johns Hopkins University Press.

Harré, Rom, 1970. The Principles of Scientific Thinking. Chicago: The University of Chicago Press.

Henry, John, 1986. "Occult Qualities and the Experimental Philosophy: Active

Principles in Pre-Newtonian Matter Theory," History of Science 24: 335-81.

Hooke, Robert, 1665. Micrographia. London.

Husserl, Edmund, 1970. The Crisis of European Sciences and Transcendental Phenomenology: An Introduction to Phenomenological Philosophy, trans. David Carc Evanston, Ill.: Northwestern University Press.

Jacob, J. R., 1977. Robert Boyle and the English Revolution: A Study in Social and Intellectual Change. New York: Burt Franklin.

- 1978. "Boyle's Atomism and the Assault on Pagan Naturalism," Social Studies of Science 8: 211-33.

Jones, Richard Foster, 1961. Ancients and Moderns: A Study of the Rise of the Scientific Movement in Seventeenth-Century England, 2d ed. St. Louis: Washington University Press.

Jordanova, L. J. and Roy S. Porter, eds., 1979. Images of the Earth: Essays in the History of the Environmental Sciences. BSHS Monographs, No. 1. Chalfont St. Giles: British Society for the History of Science.

Kargon, Robert H., 1971. "The Testimony of Nature: Boyle, Hooke and Experimental Philosophy," Albion 3: 72-81.

Kingsland, Sharon E., 1986. "Mathematical Figments, Biological Facts: Population Ecology in the Thirties," Journal of the History of Biology 19: 235-56.

Klaaren, Eugene M., 1977. Religious Origins of Modern Science: Belief in Creation in Seventeenth-Century Thought. Grand Rapids, Mich.: William B. Eerdmans.

Koyré, Alexandre, 1968. Metaphysics and Measurement: Essays in the Scientific Revolution. Cambridge, Mass.: Harvard University Press.

— , 1968a. "Pascal Savant," in idem 1968, chap. 6.

- , 1968b. "Galileo and Plato," in idem 1968, chap. 2.

Kuhn, Thomas S., 1952. "Robert Boyle and Structural Chemistry in the Seventeenth Century," Isis 43: 12-36.

- 1977. The Essential Tension: Selected Studies in Scientific Tradition and Change. Chicago: The University of Chicago Press.

- , 1977a. "Mathematical versus Experimental Traditions in the Development of

Physical Science," in idem 1977, 31 65.

- , 1977b. "The Function of Measurement in Modern Physical Science," in idem $1977,178-224$. 
Lee, Richard E., 1935. The Backgrounds and Foundations of Modern Science. Baltimore: Williams \& Wilkins.

Lindberg, David C. and G. N. Cantor, 1985. The Discourse of Light from the Middle Ages to Enlightenment. Los Angeles: William Andrews Clark Memorial Library. McGuire, J. E., 1972. "Boyle's Conception of Nature," Journal of the History of Ideas 33: 523-42.

Mach, Ernst, 1960. The Science of Mechanics, trans. Thomas J. McCormack, 6th ed. La Salle, Ill.: Open Court.

McMullin, Ernan, ed., 1978. The Concept of Matter in Modern Philosophy. Notre Dame, Ind.: Notre Dame University Press.

— , 1985. "Galilean Idealization," Studies in History and Philosophy of Science 16: 247-73.

Maddison, R. E. W., 1969. The Life of the Honourable Robert Boyle. London: Taylor and Francis.

Mahoney, Michael S., 1980. "The Beginnings of Algebraic Thought in the Seventeenth Century," in Gaukroger 1980, 141-55.

- , 1984. "Changing Canons of Mathematical and Physical Intelligibility in the Later 17th Century," Historia Mathematica 1: 417-23.

Mandelbaum, Maurice, 1964. Philosophy, Science and Sense Perception: Historical and Critical Studies. Baltimore: The Johns Hopkins Press.

— , 1964a. "Newton and Boyle and the Problem of 'Transdiction', in Mandelbaum 1964, 61-117.

Merton, Robert K., 1970. Science, Technology \& Society in Seventeenth-Century England, 2d ed. New York: Harper Torchbook.

Moran, Bruce T., 1981. "German Prince-Practitioners: Aspects in the Development of Courtly Science, Technology, and Procedures in the Renaissance," Technology and Culture 22: 253-74.

More, Louis Trenchard, 1944. The Life and Works of the Honourable Rober Boyle. London: Oxford University Press.

Naylor, Ronald, 1976. "Galileo: Real Experiment and Didactic Demonstration," Isis 67: 398-419.

Oakley, Francis, 1984. Omnipotence, Covenant, \& Order: An Excursion in the History of Ideas from Abelard to Leibniz. Ithaca: Cornell University Press.

Paracelsus, 1951. Selected Writings, ed. Jolande Jacobi, trans. Norbert Guterman. London: Routledge and Kegan Paul.

Pitt, J. C., ed., 1985. Change and Progress in Modern Science. Dordrecht: Reidel.

Power, Henry, 1664. Experimental Philosophy. London.

Pugliese, Patri Jones, 1982. "The Scientific Achievement of Robert Hooke: Method and Mechanics." Unpubl. Ph.D. thesis. Cambridge, Mass.: Harvard University.

Ravetz, J. R., 1971. Scientific Knowledge and Its Social Problems. Oxford: Clarendon Press.

Royal Society, Boyle Papers. 
Ruby, Jane E., 1986. "The Origins of Scientific 'Law'," Journal of the History of Ideas 47: 341-59.

Shapin, Steven, 1984. "Pump and Circumstance: Robert Boyle's Literary Technology," Social Studies of Science 14: 481-520.

Shapin, Steven and Simon Schaffer, 1985. Leviathan and the Air-Pump: Hobbes, Boyle, and the Experimental Life. Princeton: Princeton University Press.

Shapiro, Barbara J., 1983. Probability and Certainty in Seventeenth-Century England: A Study of the Relationships between Natural Science, Religion, History, Law, and Literature. Princeton: Princeton University Press.

Shaw, Peter, ed., 1738. The Philosophical Works of the Honourable Robert Boyle Esq. ..., 2 d ed., 3 vols. London.

- 1738a. "A General Preface to the Abridgment of Mr. Boyle's Philosophical Works," in Shaw 1738, 1: i-xxi.

Sloan, Phillip R., 1976. "The Buffon-Linnaeus Controversy," Isis 67: 356-75.

Stieb, Ernst W., 1964. "Robert Boyle's Medicina Hydrostatica and the Detection of Adulteration," in Proceedings of the Tenth International Congress of the History of Science, Ithaca, 1962, 2 vols., 2: 841-45. Paris: Hermann.

Stock, John T., 1969. The Development of the Chemical Balance. London: H.M.S.O. Stubbe, Henry, 1670. A Specimen of Some Animadversions upon a Book, Entituled, Plus Ultra, ... written by Mr. Joseph Glanvill. London.

Taton, René, ed., 1964. The Beginnings of Modern Science. From 1450 to 1800. London: Thames and Hudson.

Taton, René and I. Bernard Cohen, eds., 1964. Mélanges Alexandre Koyré. Vol. II: L'aventure de l'esprit. Paris: Hermann.

Turner, A. J., 1973. "Mathematical Instruments and the Education of Gentlemen," Annals of Science 30: 51-88.

Wallis, John, 1693-95. "Tractatus duo. Prior, De Cycloide . . ," in Opera mathematica, 2 vols., 1: 489-541. Oxford.

Webster, Charles, 1965. "The Discovery of Boyle's Law, and the Concept of Elasticity of Air in the Seventeenth Century," Archive for History of the Exact Sciences 2: 441-502.

Westfall, Richard S., 1973. Science and Religion in Seventeenth-Century England. Ann Arbor: University of Michigan Press.

Wittgenstein, Ludwig, 1976. Philosophical Investigations, trans. G.E.M. Anscombe. Oxford: Basil Blackwell.

Zetterberg, J. Peter, 1976. “ 'Mathematicall Magick' in England: 1550-1650." Unpubl. Ph.D. thesis. Madison: University of Wisconsin. 